\title{
Ethical Environment in the Online Communities by Information Credibility: A Social Media Perspective
}

\author{
Nick Hajli ${ }^{1}$
}

Received: 3 June 2015/Accepted: 20 January 2016/Published online: 2 February 2016

(c) The Author(s) 2016. This article is published with open access at Springerlink.com

\begin{abstract}
With the increasing popularity of social media, a new ethics debate has arisen over marketing and technology in the current digital era. People are using online communities but they have concern about information credibility through word of mouth in these platforms. Social media is becoming increasingly influential in shaping individuals' decision-making as more and better quality information about products is made available. In this research, a social word-of-mouth model proposes using a survey to test the model in a popular travel community. The model highlights the role of social media and social support in social networking sites (SNSs), identifying increasing credibility and information usefulness resulting in an ethical environment to adopt word of mouth. The theoretical and practical implications of the study are both detailed.
\end{abstract}

Keywords Marketing ethics - Information credibility . Social word of mouth - Social media $\cdot$ Word-of-mouth adoption · Information usefulness $\cdot$ Social support

\section{Introduction}

People in an online context have different restrictions such as not being able to touch or smell a product, which is available in traditional or offline shopping. Therefore, e-vendors develop their online platforms by providing some opportunities to consumers to share their evaluations about a product (Huang et al. 2011). These online

Nick Hajli

Nick.hajli@newcastle.ac.uk

1 Business School, Newcastle University London, London, UK platforms, such as online communities, persuade individuals to share their knowledge, experiences and information about products with peers. This develops electronic word of mouth (eWOM). eWOM content provided in these platforms is important for customers as it provides indirect experiences of a product (Do-Hyung et al. 2007). Nowadays, eWOM has been developed by the emergence of Web 2.0 technologies and the rise of social media. Enabled by social media, consumers can exchange messages through online communities (Zhang and Watts 2008), producing valuable information as a result. Information produced by individuals through social media, such as online consumer reviews, is quality information presented by customers who have experienced the product; it includes their evaluations and experiences, introducing a new form of eWOM communication (Do-Hyung et al. 2007), social word of mouth (sWOM). Social word of mouth is a new form of eWOM detailing evaluation by consumers about a product using social media (Hajli et al. 2014).

Consumers in online communities process available information produced in the networks in a contextual manner; this can be useful for the functionality of the tools in the community (Zhang and Watts 2008). This information is more influential than firm generated information, forming word of mouth (Bickart and Schindler 2001) as product know-how is facilitated (Johann et al. 2006). This can develop into an efficient new product development strategy (Füller and Matzler 2007), particularly when online WOM has high quality and relevance; it can have more influence on acceptance through WOM information (Huang et al. 2011). In addition, it can be used to increase credibility of information produced in these communities as an important factor in eWOM adoption by individuals. Credibility of information in eWOM is a key factor in marketing ethics and the adoption of information by peers 
in online communities (Hajli et al. 2014). Research shows that information produced through the social interaction of individuals facilitated by social media establishes trust for customers; the influence of this information is greater than that offered by a company (Hajli et al. 2014). Trust is a challenging factor in an online context (Kracher and Corritore 2004) and research shows trust is associated with eWOM behaviour (Chu and Kim 2011). Recent studies show that trust and issues around security in cyber space are important elements in the development of these platforms (Featherman and Hajli 2015). Other research also emphasises that security and privacy issues of individuals in social networking sites impact on the adoption of social media (Hajli and Lin 2016). Therefore, information credibility of eWOM in online communities is a fundamental issue in adoption of eWOM by consumers.

Although the available literature in eWOM discusses the impact of this marketing tool to enhance the performance of a firm, there has been little research carried out to discuss the values that social media can provide through online social support and to enhance credibility and usefulness of information produced in online communities. This is an important agenda as advancement of the internet has created new challenges for marketing ethics (Laczniak and Murphy 2006). Therefore, this research develops a social word-of-mouth adoption model to provide a better picture of members' behaviour in online communities in order to explore the strategies to enhance the ethical environment of online communities, thus developing a better marketing ethics tool for firms. As such, this study can contribute to eWOM literature and make a theoretical basis for sWOM to increase the understanding of social media and the values it can generate for marketing strategies. In particular, it can identify the strategies necessary to develop ethical information produced in online communities. More specifically, the research addresses these questions: (1) Does social media affect sWOM credibility? (2) Does social media affect information usefulness? (3) Does social media produce social support? (4) Does social support affect sWOM credibility and information usefulness? (5) Does sWOM credibility affect information usefulness? and (6) Does information usefulness and sWOM credibility affect sWOM adoption?

To address these questions, the paper is organised as follows to contribute to the body of knowledge in theory and practice. Initially the paper discusses the literature in this area and introduces sWOM. The theoretical foundations of the research and hypotheses development follow after this section with the justifications for the hypotheses. The next part contains the methodology and the way in which the validity and reliability of the study have been considered. The author finally carries out a SEM-PLS analysis to test the model and discusses the finding of the structural model. The results of this quantitative study highlight the value of social media in word-of-mouth adoption, principally for information credibility development. Finally, the theoretical and practical implications of the paper are discussed.

\section{Theoretical Background and Literature Review}

\section{Social Media Interactivity}

The literature on consumer behaviour has been researched extensively, covering the power of interpersonal relationships through WOM contacts and online communication (Herr et al. 1991). This influence has been facilitated with the worldwide availability of the internet, with the theoretical background of WOM now developed to eWOM. Additionally, the emergence of Web 2.0 technologies has provided an extensive area in the interactivity of users through social media (Cheung and Lee 2012). In particular, social media develop social interaction of individuals in an online context. Social media interactivity of individual in social networking sites develops eWOM. Social media interactivity is social interaction of people in social networking sites developed by Web 2.0 technologies such as online communities which empower people to have some interaction with their peers. Social media interactivity create marketing opportunities for firms which this research aims to look at that.

The concept of traditional WOM is broadly the same as eWOM but there are some differences between them, although both produce useful information for individuals. Traditional WOM and its influence is limited to a local network of people ( $\mathrm{Li}$ and Hitt 2008), while the information produced through online platforms has no geographical restrictions and can be accessible worldwide (DoHyung et al. 2007). In eWOM, there is no need to exchange information at the time when correspondents are present (Karakaya and Barnes 2010). It can be available online for any convenient time that consumers may need it. A good example of this is Amazon.com. Consumers can search for eWOM produced by other customers at previous times and use it at a time when they decide to buy a product. In addition, textual information provided through eWOM communication is accessible for an open-ended period of time; this capability is not available in traditional form (Park and Lee 2009). Consumers can also search for different pieces of information produced by different consumers at different times, further increasing the usefulness of eWOM and perform social media interactivity. Therefore, the improvement in communicator identification can also provide credibility to the information provided through eWOM. 


\section{Social Word of Mouth}

Electronic word of mouth is a virtual communication between consumers in an online context (Park and Lee 2009; Gruen et al. 2006). These communications are strategic and cost-effective marketing tools for business (Hajli 2015a). Additionally, the recent advancements on the internet and emergence of Web 2.0 have expanded this marketing strategy. In this era, customers have been empowered to generate word of mouth in online communities to assist firms in new product development (Fuchs and Schreier 2011). While WOM was always an important element in marketing, as shown in many pieces of research, the scope of this marketing tool is limited to a network where individuals know each other and have social interaction based on previous contacts (Hajli et al. 2014). The emergence of Web 2.0 technologies and the growth of social media have erased this limitation. As a result, sWOM has emerged with broad accessibility and the capability to be evaluated and measured by other consumers. For instance, consumers have the facility to rate and review products or read comments on the experiences of other customers who have evaluated a product. When a customer experiences a new product, such as the new IPad, and shares this experience with other users, other peers can comment on this post. Hence, this evaluation not only gives more choices and information to the network of customers but also gives an opportunity to firms to use these social interactions to improve a new product.

Social word of mouth has a unique advantage of referability, where support can be available from all around the world by a large number of individuals for an unlimited period of time. The information produced through social platforms by customers will remain online till other customers need and refer to it. The development is not limited to these users alone, but credibility of the source of WOM can also be improved by others through sWOM. Individuals use social media and online communities such as Facebook or Twitter to connect to these networks, providing contributor profile to the network; this gives more source credibility to the evaluation and participation of individuals. These advancements bring a new paradigm change to eWOM and introduce sWOM, which this research empirically examines.

\section{Online Social Support}

The time when there was a link between the lack of interpersonal relationship and the longer time an individual spent on the internet has been overtaken by the emergence of Web 2.0 technologies. The attraction of social media and intercreativity of users in SNSs have introduced a new communication tool to individuals to have social interaction worldwide with no cost involved. There is extensive literature discussing the value of online communication of individuals in online communities (Wangberg et al. 2008; Rosenfeld et al. 1989; Rhoades and Eisenberger 2002). The other contributions in this area highlight the social value of the social interaction of users in online communities and the production of social support within these networks (Obst and Stafurik 2010; Kraut et al. 2002; Hwang et al. 2010).

Social support is a theory derived from social psychology, defined as the experience of individuals to be respected, loved, helped or cared for by other members of a social network (Cobb 1976). Establishing this type of support in a social group attracts individuals to join them, as help, support and feedback in these social communities assist an individual to have a better feeling about the platform or to make better decisions once they approach a problem or an issue. This supportive environment persuades people to interact with peers about many areas in their daily lives (Laurenceau et al. 1998).

Social support is multi-dimensional, with different scholars developing various constructs in their studies. For example, it is argued that social support has appraisal, emotional, informational and instrumental dimensions (House 1981). Other scholars categorise social support as both intangible, such as emotional and informational support, and tangible support (Schaefer et al. 1981). Social media has facilitated social interaction of individuals in online communities; xxthe nature of these interactions is virtual and is based on messages containing social support, emotional support and informational support (Madjar 2008). Emotional concerns such as understanding and caring refer to emotional support (House 1981) and sharing knowledge, experiences, information or providing feedback or recommending can be defined as informational support. It is argued that informational and emotional supports are the main available supports (Hajli 2015b). Empowered by social media, consumers can interact in online communities using different Web 2.0 technologies such as forums, recommendations, ratings and reviews to access better decision and informational support in their purchase journey or receive emotional support by asking individuals to solve a problem. Hence, these types of support are the reason for examining social support in online communities.

Online social support as a new theoretical lens in the study of eWOM can be theorised based on the advancements on the internet as follows. With the availability of online social support in online communities such as TripAdvisor as an example of a travel forum, Microsoft or Dell open innovation communities or any other online communities, consumers engage in social interaction to support each other; it has become beneficial and natural for members to share their information, experiences, knowledge or provide feedback. This supportive climate can be 
applied to new product development or become part of a customer's decision-making journey to buy a product. Enabled by social media, individuals share their information; this then shapes social word of mouth in the form of informational or emotional support for the online communities. Users' perceived usefulness in terms of caring and offering support through useful information make it essential for others to seek and share commercial information within the online communities (Crocker and Canevello 2008). Hence, sharing commercial information and empathising with the issues of other members of the community is likely to produce credibility and trust in the network and the adoption of social word of mouth; this may lead to the purchase intention.

\section{Social Word-of-Mouth Adoption}

Information adoption can be defined as the process of engaging purposefully in consuming information (Cheung and Thadani 2012). Informational support provided through social interaction of individuals in online communities can be in the form of ratings, reviews, recommendations or referrals. This information may be useful for potential consumers who have not experienced a product and need independent information provided by other customers. Therefore, when consumers search for information provided by other users on online communities to make a better decision for their purchasing (Pitta and Fowler 2005), they are adopting information. This research argues that social media provides more opportunities to the individual to adopt WOM as more useful and more credible.

\section{Research Model and Hypotheses}

Based on the above literature review, the author proposes a model of antecedents to social word-of-mouth adoption in social platforms provided by social media as shown in Fig. 1. The constructs of the model are based on the impact of social media and the focus of the study is on intentions to behave. In the following section, hypotheses of the research are discussed.

\section{Direct Effect of Social Media Interactivity}

Social media enables social interaction of consumers in online platforms and offers different marketing values for firms (Rapp et al. 2013). With the advancement of Web 2.0 technologies, individuals now use social media such as SNSs to interact with each other. To join SNSs, they need to develop a profile indicating their identity and circumstances; this brings credibility to the information they provide. As identity is a key issue in online WOM that influences the credibility of eWOM (Dellarocas 2003; Forman et al. 2008), online communication of consumers through social media can impact on the reduction of uncertainty and enhance credibility in the network (Adjei et al. 2010). Therefore, firms perform eWOM marketing through online communities and blogs to increase the credibility of information produced via eWOM (Kozinets et al. 2010). In addition, consumers use social media by participating in reviewing or recommending a product to other users; these activities further increase the usefulness of a platform (Kumar and Benbasat 2006). These opportunities attract individuals to online communities and it facilitates their involvement with peers in other communities. Social interaction of consumers using social media produces social support (Obst and Stafurik 2010) as they share their knowledge, experiences and information with peers. As the voice of consumers is strong on the internet (Kaplan and Haenlein 2010), this voice has supportive value in the form of informational and emotional support. Therefore, this study investigates interactivities of people using social media, examining if this can produce social support and establish credibility of information to them. Based on this discussion, the research postulates these hypotheses:

H1 Social media interactivity is positively associated with credibility of social word of mouth.

H2 Social media interactivity is positively associated with social support.

H3 Social media interactivity is positively associated with information usefulness in online communities.

\section{Direct Effect of Social Support}

An important part of social media is continuing contact and relationships with familiar peers (Kozinets et al. 2010). The social interaction of individuals in social networking sites develops trust in an online context (Rettberg 2008) and credibility of information. Information produced in SNSs is useful and facilitates a culture of sharing amongst peers (Zhang and Watts 2008). The informational support and emotional support of peers not only facilitates enjoyment of members but also offers information usefulness as it helps them in their purchase journey and makes decisionmaking easier. Specifically, the supportive climate offers essential supports for potential customers as it has informational usefulness (Do-Hyung et al. 2007). Hence, the study postulates

H4 Social support is positively associated with social word-of-mouth credibility.

H5 Social support is positively associated with social information usefulness. 


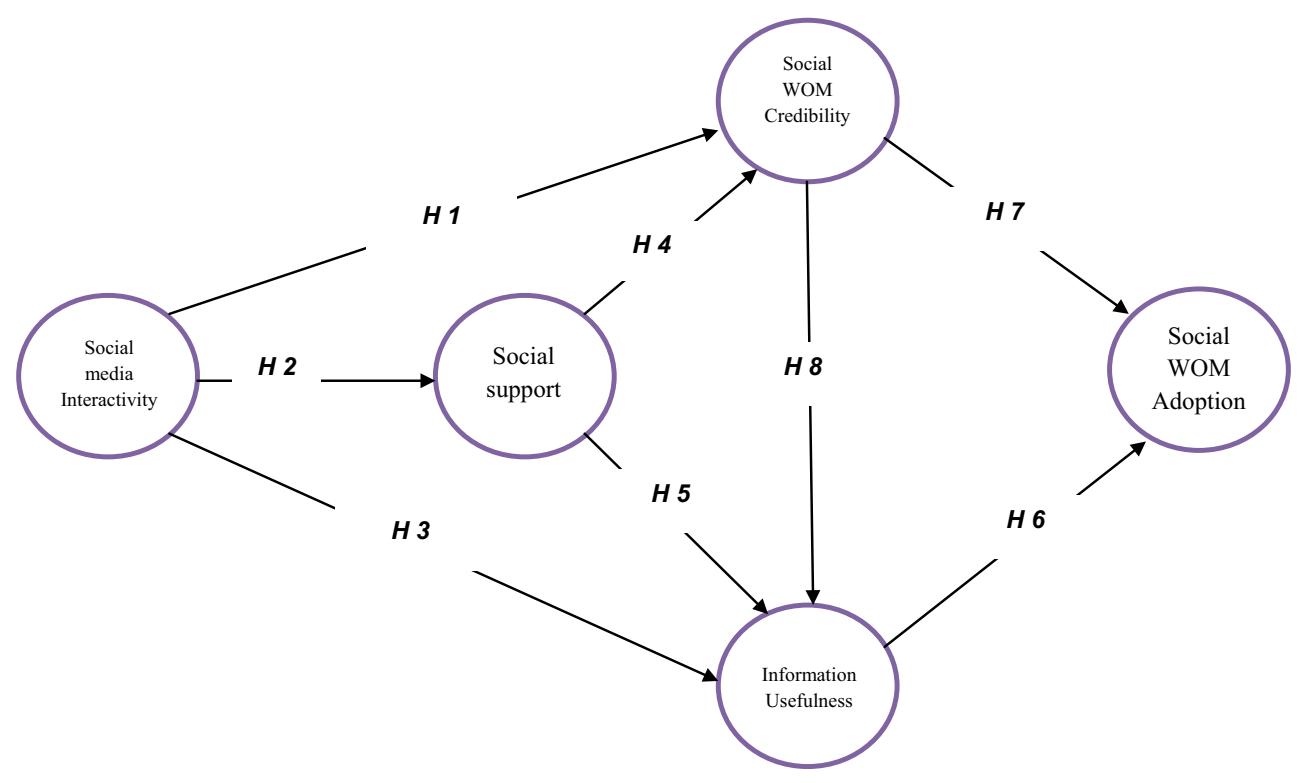

Fig. 1 Social word-of-mouth adoption model

\section{Informational Usefulness}

Community content, a natural product of interactivity of users, is an important and useful means of attracting members to share information in online communities (Zhang and Watts 2008). This also provides benefits to the members for their participation. Perceived usefulness of information provided in online forums and communities will increase information adoption (Liu and Zhang 2010; Sussman and Siegal 2003). Research shows that information usefulness has a strong impact on the decision of users to adopt WOM provided in the online communities (Cheung et al. 2008). Once individuals perceive more value, they are more likely to become involved in online WOM (de Matos and Rossi 2008). Perceived usefulness has become increasingly important with the growth in the number of SNSs and the opportunities that social media provides. Hence, the author hypothesises

H6 Perceived information usefulness is positively associated with social word-of-mouth adoption.

\section{Social WOM Credibility}

Lack of credibility in information provided to customers results in negative beliefs about firms amongst their customers (Kucuk and Krishnamurthy 2007). Therefore, credibility of the information and trust in the online communities has a significant value for the success of an online community. Recent studies in this area argue that trust within the network has significant influence on online WOM activities (de Matos and Rossi 2008). Information produced through social media, which shapes eWOM, is reflecting a mechanism to reduce uncertainty (Park and Lee 2009) and provide credibility of the information. Additionally, the higher source credibility of messages perceived in online communities provides a higher level of information adoption (Zhang and Watts 2008). Credibility of content provided through social interaction of individuals in online forums and communities makes it more influential (Bickart and Schindler 2001). Research shows that source of information credibility in an online community influences perceived usefulness of users (Cheung et al. 2008) and that higher credibility sources of information provide information usefulness (Ko et al. 2005). Therefore, these hypotheses can be postulated:

H7 The credibility of social word of mouth is positively associated with social word-of-mouth adoption.

H8 The credibility of social word of mouth is positively associated with information usefulness.

\section{Methods}

The hypotheses of the study were tested by using an online version of a survey of members of an online community, TripAdvisor. To carry out a valid investigation of subjects, the study needed to gather data from those communities that are already established and that are active and have been active for some time (Rice and Love 1987).

\section{Study Sites}

As this research focuses on the factors influencing sWOM adoption within online opinion platforms, the proposed 
model of the study was tested on existing active social platforms. An online text-based, asynchronous community was chosen for the study. This community focuses on sharing information and experiences. TripAdvisor (http://www. tripadvisor.com) is a popular online community related to reviews of hotels, flights and vacation rentals. TripAdvisor assists individuals in gathering all the information they need for travel. The community enables customers to post reviews and comments related to travel and to have interactivity with other users. The community is mature as it was founded in 2000 by a private investor. This is a user-generated content online community with free services and the business model is an advertising business model. Usage statistics indicate that this community is active and popular. By reviewing the comments related to a post in this community, the author assumed that members are active. During the initial observation of sites, the author noticed that members participate in this community by sharing their information and knowledge about a post; it was a mutual practice for individuals to use information produced in the community.

\section{Development of Measurement}

To have a higher validity, the main variables of the model have been adopted from existing measures. Appendix shows all the constructs, their sources and items of questionnaires. The table also shows the factor loading of each item. The social media interactivity constructs refer to online forums, communities, reviews and recommendations (Hajli and Lin 2016). Social support refers to emotional support and informational support, which forms social support in an online context. Social WOM adoption is measured by the process of engaging purposefully in accessing information generated by social media. Information usefulness is measured by consumers' perceived usefulness of information provided by social media such as online communities and reviews. Finally, sWOM credibility is measured by trustworthiness of content and information produced through WOM in online communities.

\section{Development of Questionnaire and Pilot Study}

A questionnaire has been developed based on the existing studies as shown in Table 1. All the questions have been adopted from recent works in this area. Initially, a pre-test study with ten students who had active membership in TripAdvisor was conducted to make sure the design of the survey is in an acceptable format. In the next step, the author invited two scholars to review the questionnaire. They had some comments on the wording of the questionnaire, which assisted the author in reducing any ambiguity of the survey. There were few amendments as the items have been previously used in other research. Three colleagues with no prior knowledge in the area have read the paper to eliminate any errors in the online version and point out any potential ambiguities in the paper. This step contributes to the content validity of the study (Wang et al. 2012). There were some issues around the understanding of question 21 "I would like to use people's online recommendations to buy a product in TripAdvisor"; the author made some minor corrections and the amended questionnaire was then sent for a pilot study. A pilot study of 20 samples, which was excluded from the main data, has been conducted in order to test the model and its constructs. The data and feedback were useful and the author refined some items in the questionnaire as a result before members were asked to fill in the questionnaire online.

\section{Survey Administration}

An online form using Google was launched. The questionnaire was online throughout May, June and July. The aim was to ensure that we can attract active participants as people make their summer vacation plans in these months. The sample pool of this research contains internet users who had recent activity in an online community of the studyTripAdvisor. These samples were randomly selected by inviting a wide range of individuals to participate in this study. We approached to different individuals through email or asking TripAdvisor users to participate on this research. A link has been posted to the online community of the study along with different messages to request members to participate in the study. A filter question in the beginning of the questionnaire helped us to remove participants with no experience of this online community. Finally, the sample of the study was collected from 333 users, with a total number of 300 usable responses. The usable responses represent participants who are active users with few missing values.

\section{Results}

Of 300 usable responses, 160 males and 140 females, most have an academic degree and were based in different countries. The respondents ranged in age from 19 to 44 years, with a mean of 30 and a standard deviation of 6.6 $(N=300)$. All the respondents mentioned that they use social networking sites and online communities to receive and share information and knowledge.

\section{Measurement Properties}

Structural equation modelling (SEM) has been employed in this research. Within the SEM approach, the study takes 
partial least square (PLS). PLS is a popular method used in business studies (Gefen et al. 2000) and if used in a proper way, it is a very efficient method (Ringle et al. 2012). PLS has the advantage of demanding minimum sample size, residual distributions and sample data distribution (Chin 1998; Chin et al. 2003).

To assess the reliability, the author examined composite reliability, with previous research suggesting that the value of 0.50 in AVE or higher is adequate (Chin et al. 2003). Table 1 shows the reliability of the measures, with all constructs greater than 0.70 . This shows that the reliability of the measures has been achieved.

For the validity of the measures, the author examined the latent constructs' validity. Convergent validity and discriminant validity were examined individually. It is recommended that AVE should be at least 0.50 (Wixom and Watson 2001). The AVE is shown in Table 1, indicating that the study has convergent validity. To test the discriminant validity, the research looks at the square roots of the AVE of latent variables to establish if these are greater than the corresponding correlations with other constructs (Chin 1998). All latent constructs are at least 0.70 and also higher than their corresponding correlations with other constructs. These are shown in Table 1.

One final step was taken to check convergent validity and discriminant validity by looking at the factor loadings of an indicator; this should be greater than the construct of any other factor (Wasko and Faraj 2005; Chin 1998). Details of the cross loading are shown in Table 2.

\section{Test of Hypotheses and Structural Model}

The hypotheses of the study were tested by examining the significance of the path coefficients of the research model. The study used SmartPLS 2.0 software to measure model fits and path coefficient. The results are shown in Fig. 2 . The results of all paths are positive and significant at the 0.05 level. The model fits; the evaluation of $R^{2}$ shows that it accounts for $38,32,24$ and $41 \%$ of the variance in sWOM credibility, information usefulness, social support and sWOM adoption. Therefore, they show an acceptable level of explanation power. Informational usefulness and sWOM credibility have both positive and significant influence on sWOM adoption. Therefore, corresponding hypotheses H6 and $\mathrm{H} 7$ are supported. The effects of social media interactivity on sWOM, social support and information usefulness are also significant and positive, which supports $\mathrm{H} 1, \mathrm{H} 2$ and H3. Social support also significantly influences social WOM credibility and information usefulness which supports $\mathrm{H} 4$ and H5. Finally, H8 is also supported as social WOM credibility influences information usefulness.

The path coefficients of constructs show that the direct effect of sWOM credibility on sWOM adoption is stronger than that of information usefulness (0.34 vs. 0.33). The path coefficients also show that social media interactivity has a stronger effect on information usefulness than sWOM credibility (0.39 vs. 0.35$)$, indicating a greater influence of social media interactivity and online communication on information usefulness. Similarly, social media interactivity has more effect on sWOM credibility than social support and information usefulness ( 0.46 vs. 0.38 and 0.37 ); this means that the social relationship of consumers can establish credibility to sWOM. Finally, social support has more influence on sWOM credibility than information usefulness (0.38 vs. 0.20). The PLS-SEM analysis also supports $\mathrm{H} 4$ and $\mathrm{H} 5$ as mediating effects of social support are positive and significant on sWOM credibility and information usefulness. Finally, sWOM credibility has a positive and significant effect on information usefulness.

\section{Discussion}

The increasing popularity of social media provides new opportunities for firms to develop their marketing strategies based on social media developments. In the present study, the author proposes a model to investigate the role of information credibility in WOM adoption. In particular, the study gathers data through a survey and a questionnaire, using PLS-SEM, to examine the relationship between constructs of the model in an online community. The results reveal that social media facilitates social interaction of individuals, with the interconnectivities of participants in
Table 1 Reliability and square of correlation between constructs

\begin{tabular}{llllll}
\hline & 1 & 2 & 3 & 4 & 5 \\
\hline Information usefulness & 0.81 & & & & \\
Social media interactivity & 0.437 & 0.76 & & & \\
Social support & 0.395146 & 0.40403 & 0.78 & & \\
Social word-of-mouth adoption & 0.532807 & 0.500248 & 0.465977 & 0.74 & 0.76 \\
Social word-of-mouth credibility & 0.370665 & 0.377346 & 0.478647 & 0.52407 & 0.563128 \\
AVE & 0.643443 & 0.565528 & 0.594975 & 0.542141 & 0.794082 \\
Composite reliability & 0.844009 & 0.838322 & 0.879681 & 0.825206 & 0. \\
\hline
\end{tabular}


Table 2 Cross loading

\begin{tabular}{|c|c|c|c|c|c|}
\hline & $\begin{array}{l}\text { Information } \\
\text { usefulness }\end{array}$ & Social support & $\begin{array}{l}\text { Social media } \\
\text { interactivity }\end{array}$ & $\begin{array}{l}\text { Social word-of- } \\
\text { mouth adoption }\end{array}$ & $\begin{array}{l}\text { Social word-of-mouth } \\
\text { credibility }\end{array}$ \\
\hline IU1 & 0.824431 & 0.280767 & 0.400875 & 0.489565 & 0.328757 \\
\hline IU2 & 0.804264 & 0.261108 & 0.267957 & 0.395269 & 0.241438 \\
\hline IU3 & 0.777047 & 0.404882 & 0.366438 & 0.38727 & 0.311068 \\
\hline SC1 & 0.223819 & 0.748233 & 0.346207 & 0.300881 & 0.34329 \\
\hline $\mathrm{SC} 2$ & 0.182085 & 0.708798 & 0.139008 & 0.298012 & 0.397913 \\
\hline SC3 & 0.356348 & 0.760124 & 0.309339 & 0.398405 & 0.24611 \\
\hline $\mathrm{SC} 4$ & 0.395533 & 0.838636 & 0.362333 & 0.422309 & 0.401974 \\
\hline SC5 & 0.328403 & 0.812086 & 0.358072 & 0.365132 & 0.447972 \\
\hline SM1 & 0.22469 & 0.238841 & 0.70707 & 0.249803 & 0.301686 \\
\hline SM2 & 0.453586 & 0.317078 & 0.774378 & 0.469091 & 0.252823 \\
\hline SM3 & 0.300839 & 0.364885 & 0.817996 & 0.290743 & 0.323604 \\
\hline SM4 & 0.307359 & 0.280593 & 0.702416 & 0.48115 & 0.26465 \\
\hline WA1 & 0.350026 & 0.144822 & 0.330216 & 0.705566 & 0.30085 \\
\hline WA2 & 0.460042 & 0.393851 & 0.36898 & 0.721335 & 0.340012 \\
\hline WA3 & 0.261749 & 0.338784 & 0.323303 & 0.754663 & 0.468709 \\
\hline WA4 & 0.473296 & 0.449558 & 0.436727 & 0.788881 & 0.426707 \\
\hline WC1 & 0.28021 & 0.312149 & 0.275934 & 0.388527 & 0.797474 \\
\hline WC2 & 0.210914 & 0.233025 & 0.263205 & 0.297407 & 0.700758 \\
\hline WC3 & 0.320731 & 0.478404 & 0.303697 & 0.460078 & 0.749906 \\
\hline
\end{tabular}

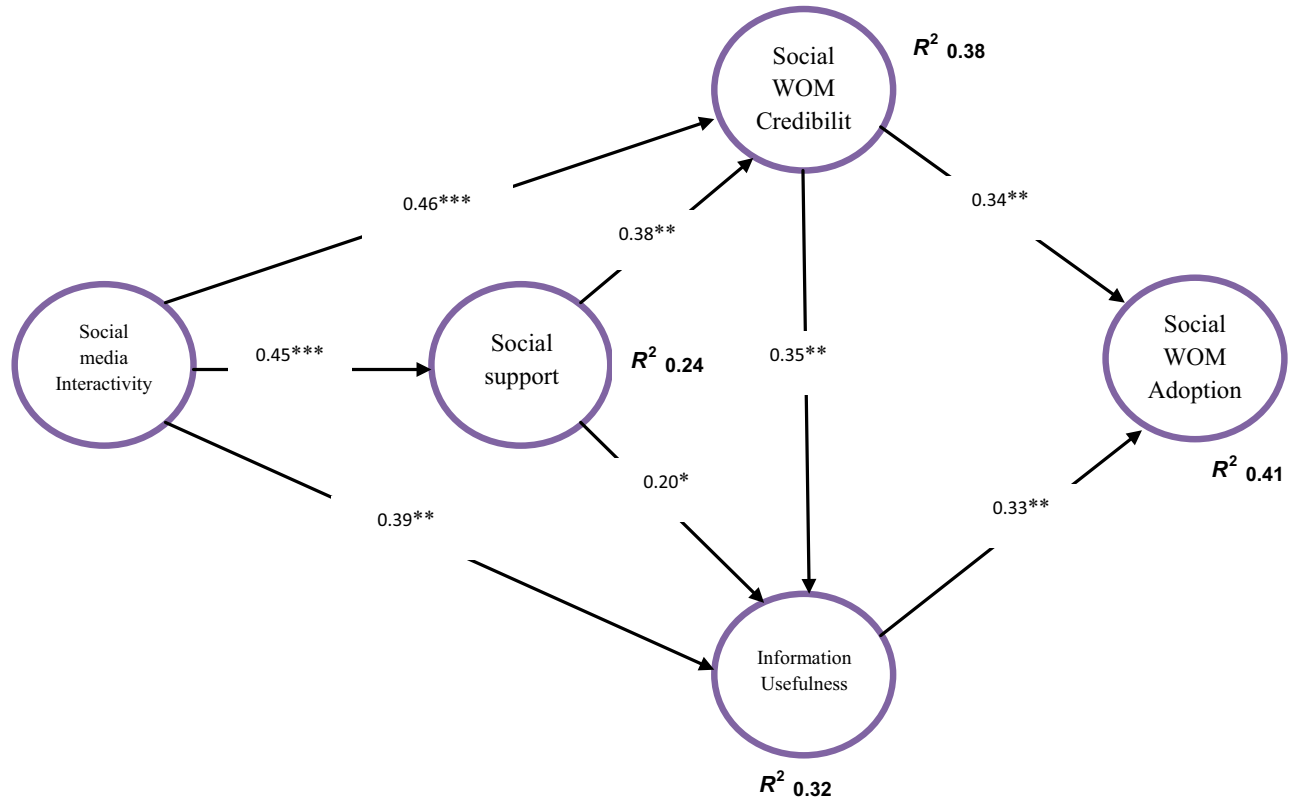

Fig. 2 Results of the PLS analysis. ${ }^{*} p<0.05$; ** $p<0.01$; *** $<0.001$

TripAdvisor producing valuable commercial information for travellers. The trustworthiness of information produced in these social climates has different values for businesses and helps develop eWOM to sWOM. The results of PLS-SEM show that social media affects credibility of information provided through sWOM. Participants use TripAdvisor to connect to their peers; to do this, they need to develop a profile in the network showing their identity. In addition, social media interactivity facilitates online communication between members of these SNSs using practical tools such as ratings, reviews, recommendations and referrals. The online communication of users helps them to reduce 
uncertainty as a key issue in an online context and to develop credibility. Social WOM credibility also establishes trust, which assists the participants to adopt sWOM. This is an important finding of this research highlighting the importance of information credibility on development of marketing ethics through online communities. The results show that social media interactivity increases credibility of sWOM; this credibility is supporting participants to adopt sWOM.

The results of this survey also show that participants employ social media by interconnecting in online travel communities to perform social interactions such as ratings, reviews, referrals or recommendation of a service to other members of the network related to tourism. Sharing information, experiences and knowledge increases perceived information usefulness by other peers who need and seek this information for their travel. Therefore, social media increases information usefulness. More interestingly, the results show that online communication of consumers produces social support for the online travel community. Emotional support and informational support are those social supports that social media facilitates in these two SNSs. These social interactions not only produce social support, but also facilitate informational support and emotional support that familiar members regularly exchange. This closeness, along with the supportive environment, increases the credibility of information produced through sWOM. These supports provide enjoyment as more users are attracted to these two SNSs and also make more information more available. It has information usefulness for those customers who have not used a new product and need customers' experience. In the case of TripAdvisor, when customers consider booking into a new hotel, they look at the ratings and reviews of other customers who have experience of the hotel. This information, provided by ratings and reviews or recommendations and referrals, brings credibility and usefulness to WOM produced in SNSs and helps them to adopt sWOM. The results reveal that participant adoption of WOM produced by social media increases when they perceive information usefulness. Therefore, social media increases information usefulness facilitated by sWOM.

\section{Theoretical Implication}

Developing theoretical debate of technology and marketing ethics using Web 2.0 technology to challenges such as information credibility is the main contribution of this research. Integrating social support theory from social psychology stream, information usefulness from information systems track and social media concept from marketing to investigate information credibility of social word of mouth in online communities may give a new theoretical direction to marketing ethics research. The study also develops eWOM to social WOM using social support theory and a social media perspective. In this paper, the author establishes a new theoretical background for eWOM using social media to explore the ethics debate of marketing and technology. The use of social media and social support theory, given the popularity of SNSs and the increasing attraction of these online platforms, can be a theoretical development in eWOM. The study also proposes and validates a social word-of-mouth adoption model; this makes a sound basis for future research.

\section{Practical Implications}

The literature of WOM has developed the motivation to perform eWOM and the factors involved drive customers to use it. However, the present research examined how social media developed eWOM to social WOM and how consumers are motivated to spread its use and derive benefit from it by having information credibility. Therefore, the present paper expects the findings of this research to provide a better picture to firms of how to develop their social media strategies in an ethical environment by developing information credibility in an online community; this will identify more mechanisms for the business sector to expand in new product development or new market entry for example. This will help firms to use social media to attract more customers and facilitate their social interactions to produce social word of mouth for their products. They may develop their marketing strategies based on a social media perspective to distribute their information along a different route to their customers. This information has more influence than other sources such as a website or eWOM since before using social media, customers need to establish a credible profile. This identity, a critical point of eWOM, can be achieved by social media. This gives a new marketing strategy using social media to develop sWOM to increase the credibility of information produced through online communication. Credibility is an important factor as customers cannot experience the products and services in an online context. Therefore, sWOM can produce credible information for the network. E-vendors can develop online communities to attract individuals to come online and perform social interaction with their peers. In the case of new product development, businesses can use social media to facilitate social interaction of consumers, especially those who have experienced a new product. These customers may detail their experiences, information and knowledge about a new product, a valuable source of information for non-experienced customers. This supportive environment provides informational support and emotional support, establishing information credibility and usefulness leading to sWOM adoption. Finally, this study identifies a deeper understanding of online travel communities, as travellers now seek improved and better quality services. Social media provides them with the tools to do this. 


\section{Limitation}

Similar to other studies, the research has some limitations. Initially, the paper uses only one online travel community. Any future research should test the model using different online communities, specifically those for new product development. The model can be a useful theoretical foundation for the use of information systems to enable open innovation. Future research may use this model to investigate how social media can enable open innovation, for example, for market entry or new product development.

\section{Conclusion}

The increasing popularity of social media has attracted many individuals to social networking sites to engage in social interaction and share their information and knowledge with their peers. However, people have concerns over the use of information in online communities and credibility of information produced in online communities. In this research, the author has adopted the electronic word-of-mouth theory and the social support theory along with a social media perspective to investigate how social interaction of consumers through social media can affect a consumer's social word-of-mouth adoption by information credibility. The study conducted a survey using PLS-SEM to test the model. The results of the empirical research show that social media interactivity significantly influences credibility and usefulness of information. More specifically, the study makes a theoretical development of eWOM to social word of mouth. Social WOM facilitates the evaluation by consumers about a product using social media. The research shows that sWOM has emerged with broad accessibility and the capability to be evaluated and measured easily by other consumers. The information produced through social media will remain online till other customers need and refer to it. The study also gives practical implications to the business sector on how to use social media to develop online communities. This helps firms to establish social support, credibility and usefulness of information leading to sWOM adoption, more particularly for new product development.

Open Access This article is distributed under the terms of the Creative Commons Attribution 4.0 International License (http://creative commons.org/licenses/by/4.0/), which permits unrestricted use, distribution, and reproduction in any medium, provided you give appropriate credit to the original author(s) and the source, provide a link to the Creative Commons license, and indicate if changes were made.

\section{Appendix}

See Table 3.

Table 3 Research constructs and factor loadings

\begin{tabular}{|c|c|c|}
\hline Codes & Scales & Factor loading \\
\hline \multicolumn{3}{|c|}{ Social support } \\
\hline \multicolumn{3}{|c|}{ Adapted from Liang et al. (2011) } \\
\hline \multicolumn{3}{|c|}{ Emotional support } \\
\hline $\mathrm{SC} 1$ & When faced with difficulties, some people on TripAdvisor comforted and encouraged me & 0.75 \\
\hline $\mathrm{SC} 2$ & $\begin{array}{l}\text { When faced with difficulties, some people on TripAdvisor expressed interest } \\
\text { and concern in my well-being }\end{array}$ & 0.71 \\
\hline \multicolumn{3}{|c|}{ Informational support } \\
\hline $\mathrm{SC} 3$ & On TripAdvisor, some people would offer suggestions when I needed help & 0.77 \\
\hline $\mathrm{SC} 4$ & $\begin{array}{l}\text { When I encountered a problem, some people on TripAdvisor would give me } \\
\text { information to help me overcome the problem }\end{array}$ & 0.84 \\
\hline SC5 & $\begin{array}{l}\text { When faced with difficulties, some people on TripAdvisor would help me discover } \\
\text { the cause and provide me with suggestions }\end{array}$ & 0.82 \\
\hline \multicolumn{3}{|c|}{ Social word-of-mouth credibility } \\
\hline \multicolumn{3}{|c|}{ Adapted from (Gefen 2000) } \\
\hline WC1 & I think review is factual & 0.80 \\
\hline WC2 & I think review is accurate & 0.71 \\
\hline WC3 & I think review is credible & 0.75 \\
\hline \multicolumn{3}{|c|}{ Social media interactivity } \\
\hline \multicolumn{3}{|c|}{ Adapted from (Hajli 2015a) } \\
\hline SM1 & I will ask my friends on TripAdvisor to provide me with their suggestions before I go shopping & 0.71 \\
\hline SM2 & I am willing to recommend a service that is worth buying to my friends on the community & 0.78 \\
\hline SM3 & $\begin{array}{l}\text { I am willing to share my own shopping experience with my friends on TripAdvisor or through } \\
\text { ratings and reviews }\end{array}$ & 0.82 \\
\hline
\end{tabular}


Table 3 continued

\begin{tabular}{lll}
\hline Codes & Scales & Factor loading \\
\hline SM4 & I would like to use people's online recommendations to buy a product in TripAdvisor & 0.71 \\
Information usefulness & & 0.825 \\
Adapted from Sussman and Siegal (2003) & The information in this community is valuable \\
IU1 & The information in this community is informative & 0.805 \\
IU2 & The information in this community is helpful \\
IU3 & Have you acted on the content of TripAdvisor? & 0.778 \\
Social word-of-mouth adoption & 0.71 \\
Adapted from Sussman and Siegal (2003), Gefen and Straub (2000) \\
WA1 & To what extend does the content of TripAdvisor motivate you to take action? \\
WA2 & Review made it easier for me to make the purchase decision. (e.g. purchase or not purchase) \\
WA3 & 0.73 \\
WA4 & 0.76 \\
\hline
\end{tabular}

\section{References}

Adjei, M., Noble, S., \& Noble, C. (2010). The influence of C2C communications in online brand communities on customer purchase behavior. Journal of the Academy of Marketing Science, 38(5), 634-653. doi:10.1007/s11747-009-0178-5.

Bickart, B., \& Schindler, R. M. (2001). Internet forums as influential sources of consumer information. Journal of Interactive Marketing, 15(3), 31-40.

Cheung, C. M. K., \& Lee, M. K. O. (2012). What drives consumers to spread electronic word of mouth in online consumer-opinion platforms. Decision Support Systems, 53(1), 218-225. doi:10. 1016/j.dss.2012.01.015.

Cheung, C. M., Lee, M. K., \& Rabjohn, N. (2008). The impact of electronic word-of-mouth: The adoption of online opinions in online customer communities. Internet Research, 18(3), 229-247.

Cheung, C. M. K., \& Thadani, D. R. (2012). The impact of electronic word-of-mouth communication: A literature analysis and integrative model. Decision Support Systems, 54(1), 461-470. doi:10.1016/j.dss.2012.06.008.

Chin, W. W. (1998). Issues and opinion on structural equation modeling. MIS Quarterly, 22, 1.

Chin, W. W., Marcolin, B. L., \& Newsted, P. R. (2003). A partial least squares latent variable modeling approach for measuring interaction effects: Results from a Monte Carlo simulation study and an electronic-mail emotion/adoption study. Information Systems Research, 14(2), 189-217.

Chu, S.-C., \& Kim, Y. (2011). Determinants of consumer engagement in electronic word-of-mouth (eWOM) in social networking sites. International Journal of Advertising, 30(1), 47-75. doi:10.2501/ IJA-30-1-047-075.

Cobb, S. (1976). Presidential address-1976. Social support as a moderator of life stress. Psychosomatic Medicine, 38(5), 300-314.

Crocker, J., \& Canevello, A. (2008). Creating and undermining social support in communal relationships: The role of compassionate and self-image goals. Journal of Personality and Social Psychology, 95(3), 555-575.

de Matos, C. A., \& Rossi, C. A. V. (2008). Word-of-mouth communications in marketing: a meta-analytic review of the antecedents and moderators. Academy of Marketing Science Journal, 36(4), 578-596. doi:10.1007/s11747-008-0121-1.
Dellarocas, C. (2003). The digitization of word of mouth: Promise and challenges of online feedback mechanisms. Management Science, 49(10), 1407-1424.

Do-Hyung, P., Jumin, L., \& Ingoo, H. (2007). The effect of on-line consumer reviews on consumer purchasing intention: The moderating role of involvement. International Journal of Electronic Commerce, 11(4), 125-148. doi:10.2753/jec10864415110405.

Featherman, M. S., \& Hajli, N. (2015). Self-service technologies and e-services risks in social commerce era. Journal of Business Ethics, 2015, 1-19.

Forman, C., Ghose, A., \& Wiesenfeld, B. (2008). Examining the relationship between reviews and sales: The role of reviewer identity disclosure in electronic markets. Information Systems Research, 19(3), 291-313.

Fuchs, C., \& Schreier, M. (2011). Customer empowerment in new product development. Journal of Product Innovation Management, 28(1), 17-32. doi:10.1111/j.1540-5885.2010.00778.x.

Füller, J., \& Matzler, K. (2007). Virtual product experience and customer participation-A chance for customer-centred, really new products. Technovation, 27(6-7), 378-387. doi:10.1016/j. technovation.2006.09.005.

Gefen, D. (2000). E-commerce: The role of familiarity and trust. Omega, 28(6), 725-737.

Gefen, D., \& Straub, D. (2000). The relative importance of perceived ease of use in IS adoption: A study of e-commerce adoption. Journal of the Association for Information Systems, 1, 8.

Gefen, D., Straub, D. W., \& Boudreau, M.-C. (2000). Structural equation modeling and regression: Guidelines for research practice. In Communications of the association for information systems: Citeseer.

Gruen, T. W., Osmonbekov, T., \& Czaplewski, A. J. (2006). eWOM: The impact of customer-to-customer online know-how exchange on customer value and loyalty. Journal of Business Research, 59(4), 449-456.

Hajli, N. (2015a). Social commerce constructs and consumer's intention to buy. International Journal of Information Management, 35(2), 183-191.

Hajli, N. (2015b). Handbook of research on integrating social media into strategic marketing (pp. 1-440). Hershey, PA: IGI Global. doi:10.4018/978-1-4666-8353-2. 
Hajli, N., \& Lin, X. (2016). Exploring the security of information sharing on social networking sites: The role of perceived control of information. Journal of Business Ethics, 133(1), 111-123.

Hajli, N., Lin, X., Featherman, M., \& Wang, Y. (2014). Social word of mouth: How trust develops in the market. International Journal of Market Research, 56(5), 673-689.

Herr, P. M., Kardes, F. R., \& Kim, J. (1991). Effects of word-ofmouth and product-attribute information on persuasion: An accessibility-diagnosticity perspective. Journal of Consumer Research, 17, 454-462.

House, J. S. (1981). Work stress and social support. Reading: Addison-Wesley Publishing Company.

Huang, M., Cai, F., Alex, S. L. T., \& Zhou, N. (2011). Making your online voice loud: the critical role of WOM information. European Journal of Marketing, 45(7/8), 1277-1297. doi:10. 1108/03090561111137714.

Hwang, K. O., Ottenbacher, A. J., Green, A. P., Cannon-Diehl, M. R., Richardson, O., Bernstam, E. V., et al. (2010). Social support in an internet weight loss community. International Journal of Medical Informatics, 79(1), 5-13. doi:10.1016/j.ijmedinf.2009. 10.003 .

Johann, F., Bartl, M., Ernst, H., \& Hans, M. (2006). Community based innovation: How to integrate members of virtual communities into new product development. Electronic Commerce Research, 6(1), 57-73.

Kaplan, A. M., \& Haenlein, M. (2010). Users of the world, unite! The challenges and opportunities of social media. Business Horizons, 53(1), 59-68. doi:10.1016/j.bushor.2009.09.003.

Karakaya, F., \& Barnes, N. G. (2010). Impact of online reviews of customer care experience on brand or company selection. Journal of Consumer Marketing, 27(5), 447-457.

Ko, D.-G., Kirsch, L. J., \& King, W. R. (2005). Antecedents of knowledge transfer from consultants to clients in enterprise system implementations. MIS Quarterly, 29, 59-85.

Kozinets, R. V., de Valck, K., Wojnicki, A. C., \& Wilner, S. J. S. (2010). Networked narratives: Understanding word-of-mouth marketing in online communities. Journal of Marketing, 74(2), 71-89. doi:10.1509/jmkg.74.2.71.

Kracher, B., \& Corritore, C. L. (2004). Is there a special e-commerce ethics? Business Ethics Quarterly, 14, 71-94.

Kraut, R., Kiesler, S., Boneva, B., Cummings, J., Helgeson, V., \& Crawford, A. (2002). Internet paradox revisited. Journal of social issues, 58(1), 49-74.

Kucuk, S. U., \& Krishnamurthy, S. (2007). An analysis of consumer power on the internet. Technovation, 27(1-2), 47-56. doi:10. 1016/j.technovation.2006.05.002.

Kumar, N., \& Benbasat, I. (2006). Research note: the influence of recommendations and consumer reviews on evaluations of websites. Information Systems Research, 17(4), 425-439.

Laczniak, G. R., \& Murphy, P. E. (2006). Marketing, consumers and technology: Perspectives for enhancing ethical transactions. Business Ethics Quarterly, 16(3), 313-321. doi:10.2307/3857918.

Laurenceau, J.-P., Barrett, L. F., \& Pietromonaco, P. R. (1998). Intimacy as an interpersonal process: The importance of selfdisclosure, partner disclosure, and perceived partner responsiveness in interpersonal exchanges. Journal of Personality and Social Psychology, 74(5), 1238-1251.

Li, X., \& Hitt, L. M. (2008). Self-selection and information role of online product reviews. Information Systems Research, 19(4), $456-474$.

Liang, T.-P., Ho, Y.-T., Li, Y.-W., \& Turban, E. (2011). What drives social commerce: The role of social support and relationship quality. International Journal of Electronic Commerce, 16(2), 69-90.

Liu, R. R., \& Zhang, W. (2010). Informational influence of online customer feedback: An empirical study. Journal of Database Marketing \& Customer Strategy Management, 17(2), 120-131.

Madjar, N. (2008). Emotional and informational support from different sources and employee creativity. Journal of Occupational and Organizational Psychology, 81(1), 83-100.

Obst, P., \& Stafurik, J. (2010). Online we are all able bodied: Online psychological sense of community and social support found through membership of disability-specific websites promotes well-being for people living with a physical disability. Journal of Community \& Applied Social Psychology, 20(6), 525-531. doi:10.1002/casp.1067.

Park, C., \& Lee, T. M. (2009). Information direction, website reputation and eWOM effect: A moderating role of product type. Journal of Business Research, 62(1), 61-67.

Pitta, D. A., \& Fowler, D. (2005). Online consumer communities and their value to new product developers. The Journal of Product and Brand Management, 14(4/5), 283-291.

Rapp, A., Beitelspacher, L., Grewal, D., \& Hughes, D. (2013). Understanding social media effects across seller, retailer, and consumer interactions. Journal of the Academy of Marketing Science, doi:10.1007/s11747-013-0326-9.

Rettberg, J. W. (2008). Blogging. Cambridge: Polity.

Rhoades, L., \& Eisenberger, R. (2002). Perceived organizational support: A review of the literature. Journal of Applied Psychology, 87(4), 698-714. doi:10.1037/0021-9010.87.4.698.

Rice, R. E., \& Love, G. (1987). Electronic emotion socioemotional content in a computer-mediated communication network. Communication Research, 14(1), 85-108.

Ringle, C. M., Sarstedt, M., \& Straub, D. W. (2012). Editor's comments: A critical look at the use of PLS-SEM in MIS quarterly. MIS Quarterly, 36(1), iii-xiv.

Rosenfeld, L. B., Richman, J. M., \& Hardy, C. J. (1989). Examining social support networks among athletes: Description and relationship to stress. The Sport Psychologist, 3(1), 23-33.

Schaefer, C., Coyne, J. C., \& Lazarus, R. S. (1981). The health-related functions of social support. Journal of Behavioral Medicine, 4(4), 381-406.

Sussman, S. W., \& Siegal, W. S. (2003). Informational influence in organizations: an integrated approach to knowledge adoption. Information Systems Research, 14(1), 47-65.

Wang, X., Yu, C., \& Wei, Y. (2012). Social media peer communication and impacts on purchase intentions: A consumer socialization framework. Journal of Interactive Marketing, 26(4), 198-208. doi:10.1016/j.intmar.2011.11.004.

Wangberg, S. C., Andreassen, H. K., Prokosch, H.-U., Santana, S. M. V., Sørensen, T., \& Chronaki, C. E. (2008). Relations between Internet use, socio-economic status (SES), social support and subjective health. Health Promotion International, 23(1), 70-77. doi:10.1093/heapro/dam039.

Wasko, M. M., \& Faraj, S. (2005). Why should i share? Examining social capital and knowledge contribution in electronic networks of practice. MIS Quarterly, 29(1), 35-57.

Wixom, B. H., \& Watson, H. J. (2001). An empirical investigation of the factors affecting data warehousing success. MIS Quarterly, 25(1), 17-41.

Zhang, W., \& Watts, S. A. (2008). Capitalizing on content: Information adoption in two online communities. Journal of the Association for Information Systems, 9(2), 73-94. 